\section{An inexpensive operant chamber interface for the VIC 20 microcomputer}

\author{
EDWARD K. CROSSMAN \\ Utah State University, Logan, Utah
}

An inexpensive interface to connect the VIC 20 (or other Commodore microcomputer) to a single operant chamber is described. This interface is equipped to accept as inputs three separate switch closures and produces five outputs, including one to elevate a food hopper. The uses of this interface for controlling experimental events and acquiring data in real time are discussed.

It is neither difficult nor expensive (less than $\$ 50$ ) to construct an interface that allows the Commodore VIC 20 microcomputer to control a three-key animal operant conditioning chamber, and to acquire response and event data in real time. (The VIC 20 contains a real-time clock with $1 / 60$-sec resolution.) This interface has three inputs for three separate key-microswitches and has five outputs. Three of the outputs control each of three keylights, one controls the houselight, and one, a high current output (1 A), drives the feeder mechanism. McLean (1978) described a similar interface for the PET microcomputer. As data are input, the clock is read and the events are stored on cassette tape or floppy disk.

The interface attaches to the user (parallel) port of the VIC 20 . The user port lines utilized by this interface are the same for the VIC 20, the many PET/CBM models, and the Commodore 64.

In addition to the parts required for the interface, a $5-\mathrm{V}$ dc $1-\mathrm{A}$ power supply and a $28-\mathrm{V}$ dc $1-\mathrm{A}$ power supply are required. We found it best to use separate $5-\mathrm{V}$ dc and $28-\mathrm{V}$ dc power supplies for each system (VIC 20-interface-operant chamber). Even though the utilization of one of these complete systems per chamber may be almost as expensive as a centralized system that uses a single, larger computer to control multiple chambers, decentralization has two advantages: (1) chambers can be placed at many different locations, and (2) if one system fails, the research in the other chambers is not interrupted.

Figure 1 shows a diagram of the complete interface. Basically, the circuit consists of two 75452 ICs for turning the lights off or on, one 7414 IC primarily for

The author expresses thanks to Doug Woodhead, Todd Daun, and Gregory Yob for advice and assistance in this project, and to Elliott Bonem for commenting on the manuscript. The author's mailing address is: Department of Psychology, Utah State University, Logan, UT 84322.

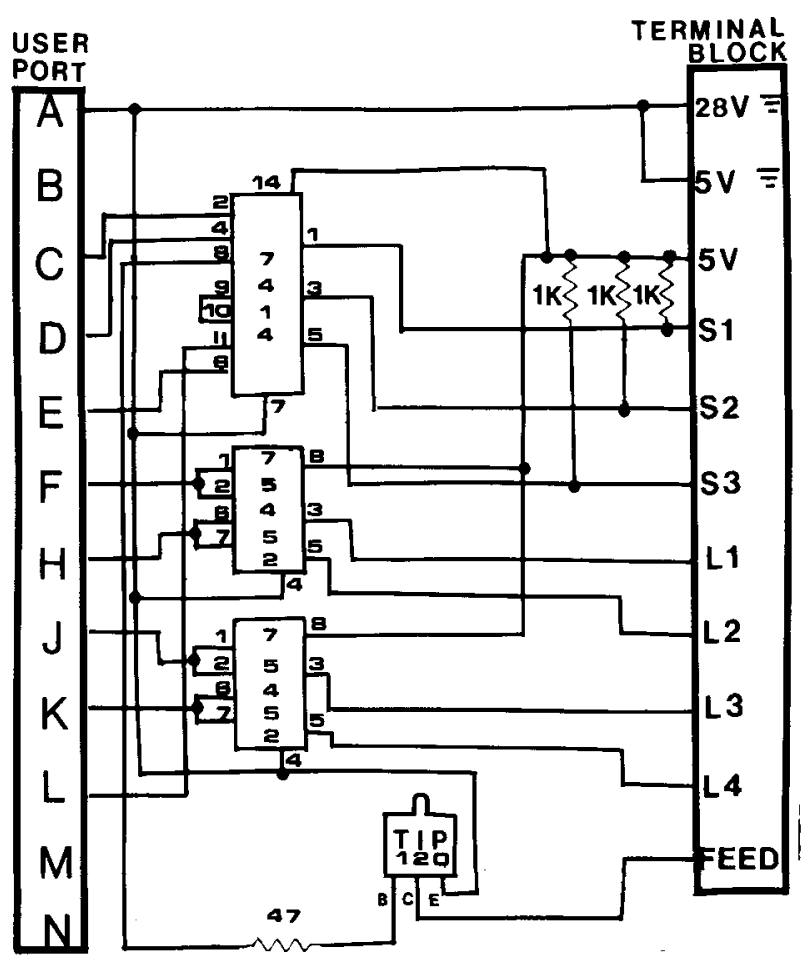

Figure 1. VIC 20 interface circuit. The letters "B," "C," and "E" below the TIP 120 transistor refer to base, collector, and emitter, respectively. The letters " $S$ " and " $L$ " on the terminal block refer to switch and lamp, respectively. Note, user port connections $B, M$, and $N$ are not used.

the response keys, and one TIP 120 power transistor to drive the feeder. The ICs are placed in sockets, so they can be easily replaced if necessary, and a combination of wire wrapping and soldering is used to make the connections. A commercial socket is not available for the TIP 120, and care should be exercised if soldering heat is applied to the three leads (base, collector, and emitter). The edge connector, which plugs into the user port, is a Sullins ESM12DREN and is glued (epoxy) to the underside of a $4.5 \times 5.5$ in. piece of breadboard with holes spaced $0.1 \mathrm{in}$. apart. At the other side of the interface, a screw-type terminal block is glued to the topside of the breadboard, and its wire-wrap (or solder) terminals project through the breadboard to the underside. All connections are made on the underside. Wires with $\mathrm{Nu}$-Way snaps on one end and bare wire (insulation removed) on the other end connect the operant chamber's connection panel to the interface's terminal block. The interface should be supported at the terminalblock end so that the weight of the interface board does not crack the VIC 20 motherboard. 
Table 1

VIC 20 User Port Designations

\begin{tabular}{lllllllll}
\hline & \multicolumn{10}{c}{ Connector Pins } \\
\cline { 2 - 8 } & \multicolumn{1}{c}{ L } & K & J & H & F & E & D & C \\
\hline User port data lines & PB 7 & PB 6 & PB 5 & PB 4 & PB 3 & PB 2 & PB 1 & PB 0 \\
Device attached & FEEDER & L4 & L3 & L2 & L1 & SW 3 & SW 2 & SW 1 \\
Weighting (decimal) & 128 & 64 & 32 & 16 & 8 & 4 & 2 & 1 \\
\hline
\end{tabular}

Operating the Interface. The BASIC commands PEEK and POKE are used to receive signals from or send signals to the user port. Table 1 shows the connector pins, user port data lines, the device attached to each line, and the decimal number (binary-coded decimal) that represents the weighting code for each line.

The functions of two locations in the VIC 20 are as follows: Location 37138 , known as the data direction register (DDR), determines which of the eight user port data lines are inputs and which are outputs. By placing the number 248 in this location (POKE37138, 248), data lines PB0 through PB2 will be input lines and PB3 through PB7 will be output lines. This particular POKE instruction is performed at the beginning of the BASIC program and need not be repeated.

Location 37136 is the address of the user port. POKEing a number in this location turns on the chamber lights and/or feeder. For example, POKE37136, 8 turns on Lamp 1 ( $\mathrm{Ll}$ in Table 1). POKE37136, 0 turns off Lamp 1 (as well as any other devices that may have been on). To turn on two devices at the same time, it is necessary to POKE the sum of the weighted values for the respective devices. Thus, to turn on both Lamp 1 and the feeder, it is necessary to POKE37136, $136(128+8)$.

To detect a switch closure, it is necessary to read the user port location with the PEEK command. Thus, $\mathrm{A}=$ PEEK (37136) assigns to the variable A whatever value was in location 37136 at the time this command was executed. However, it is only lines PBO, PB1, and PB2 that need to be examined for a switch closure. This is accomplished by the following sequence of commands:

\section{IF (PEEK (37136) AND 1) THEN PRINT "SW 1 WAS CLOSED" \\ 20 IF (PEEK (37136) AND 2) THEN PRINT “SW 2 WAS CLOSED" \\ 30 IF (PEEK (37136) AND 4) THEN PRINT "SW 3 WAS CLOSED"}

The logical AND portion of the instruction masks off all bits (lines) except the data line currently being examined. If another type of Commodore computer is used, the PEEK and POKE locations will be different, and a comprehensive user manual should be consulted.

It is necessary to debounce the microswitch signal to avoid recording multiple closures when the switch has been operated only one time. Also, because there is no pulse former (one-shot) in the interface, if the microswitch is held in a closed position, multiple closures will be recorded. Both of these problems are easily handled with software. The following program checks the status of each of two keys:

10 IF (PEEK (37136) AND 1) THEN 30
20 GO TO 50
30 IF (PEEK (37136) AND 1) THEN 30
40 PRINT "SW 1 WAS CLOSED"
50 IF (PEEK (37136) AND 2) THEN 70
60 GO TO 90
70 IF (PEEK (37136) AND 2) THEN 70
80 PRINT "SW 2 WAS CLOSED"

and so forth.

In this sequence of instructions, when a 1 (high) is detected (indicating a switch closure) on a particular data line (see program lines 10 and 50), the program will not examine another data line until a transition to a

Table 2

Examples of Events Written to Disk

\begin{tabular}{cl}
\hline $\begin{array}{c}\text { Event on } \\
\text { Disk }\end{array}$ & \multicolumn{1}{c}{ Meaning } \\
\hline A360 & $\begin{array}{l}\text { Lamp on left key was turned on at 360/60ths of } \\
\text { a second after session started. }\end{array}$ \\
B1200 & $\begin{array}{l}\text { Response occurred at 1200/60ths of a second } \\
\text { after session started. }\end{array}$ \\
C1202 & $\begin{array}{l}\text { Hopper was raised at 1202/60ths of a second } \\
\text { after session started. }\end{array}$ \\
\hline
\end{tabular}

Table 3

Sample FR 10 Program for VIC 20

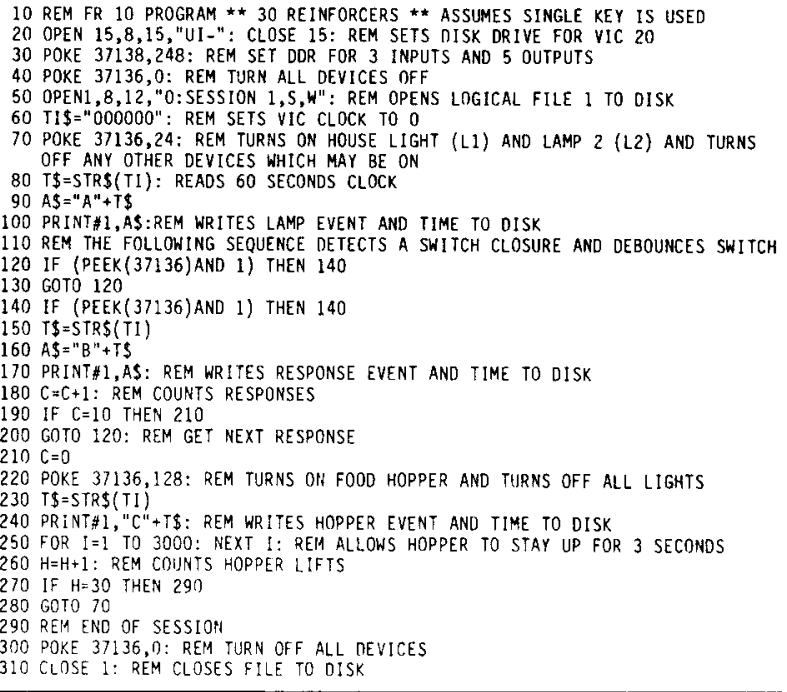


0 (low) has occurred on that same data line (see program lines 30 and 70 ).

Data Recording. Each time a new event occurs, that event and the time it occurred are written to disk (or tape). Each event is coded with a unique letter and concatenated with the event time before the writing occurs. (See Table 2 for examples.)

By coding in this fashion, it is relatively simple to calculate interresponse times (IRTs), postreinforcement pauses (PRPs), or other frequency or temporal measures after the session has been completed. A complete fixedratio (FR) 10 program is shown in Table 3.

The primary advantages of the system are simplicity, low cost, and reliability. We have used several of these systems for 9 months with no problems and no loss of data, even when high pigeon pecking rates are input.
Even though the VIC 20 has only $5 \mathrm{~K}$ of user memory, judicious programming techniques and the fact that response and event data are written immediately to disk (or tape) have made this small memory size no problem. (Additional memory can be added to the VIC 20 for less than $\$ 100$.) Also, by programming exclusively in the simple BASIC language, it is easy to teach students how to operate the system.

\section{REFERENCE}

McLean, R. S. (1978). The Commodore PET: Using personal computers for experimental control. Behavior Research Methods \& Instrumentation, 10, 468-473.

(Manuscript accepted for publication June 15, 1984.) 